\title{
LA LEGISLACIÓN CANÓNICA Y EL MATRIMONIO DE ESCLAVOS EN LA AMÉRICA ESPAÑOLA Y LA AMÉRICA PORTUGUESA
}

\author{
Yobani Maikel Gonzales Jauregui*
}

\begin{abstract}
Resumen: Las monarquías católicas en su conquista del Nuevo Mundo buscaron crear sociedades católicas y esclavistas al mismo tiempo. Generándose documentos conciliares que limitaban el poder de los amos sobre los hombres esclavizados. Estos documentos eran el Tercer Concilio Límense (1582) y Las Constituciones del Arzobispado de Bahía (1707), esta diferencia de más de un siglo tuvo un impacto significativo porque mientras en Lima colonial, se castigaba con la excomunión a los amos que impedían los matrimonios de sus esclavizados, en el Brasil colonial, no existía una pena contra los amos infractores. Hecho que convirtió los derechos a la libertad de elección y la indisolubilidad matrimonial en concesiones señoriales.
\end{abstract}

Palabras-claves: Esclavitud, derecho eclesiástico, excomunión, América española y América Portuguesa.

\section{THE CANONIAN LEGISLATION AND THE MARRIAGE OF SLAVES IN SPANISH AMERICA AND PORTUGUESE AMERICA}

\begin{abstract}
During the conquest of the New World, the catholic monarchies aimed to create catholic and slave societies. From that, there was the creation of documents that limited the power masters had over slaves. These documents were The Third Council of Lima (1582) and The Constitutions of the Archdiocese of Bahia (1707). This difference of more than a century had a significant impact, since, whilst in Colonial Lima the masters that impeded their slaves' marriage were punished with excommunication, in Colonial Brazil there was no punishment against the offending masters. This event turned the rights to freedom of choice and indissolubility into stately concessions.
\end{abstract}

Keywords: Slavery, Ecclesiastic Right, Excommunication, Spanish America and Portuguese America.

\footnotetext{
* Doutorando em História na Universidade Federal de Juiz de Fora. Bolsista de monitoria da Universidade Federal de Juiz de Fora.
} 


\section{INTRODUCCIÓN}

Las investigaciones sobre los discursos religiosos a favor de la población esclavizada en el periodo colonial han sido tratadas de forma tangencial por la historiografía latinoamericana. En las monarquías ibéricas se buscó construir sociedades católicas y esclavistas a la vez. Por ese motivo, desde la Iglesia emanaron disposiciones legales a favor de los esclavizados, reconociéndoles sus derechos al bautismo, la asistencia a misa, la libertad de elección del cónyuge y a la indisolubilidad del matrimonio. Estas disposiciones eclesiásticas tuvieron como base el discurso del Concilio de Trento, que elevó el matrimonio a categoría de sacramento, pasando así a ser de control exclusivo de la Iglesia. Tales disposiciones fueron replicadas en varios documentos coloniales, entre ellos, los Concilios Limenses, los Concilios Provinciales Mexicanos y las Constituciones del Arzobispado de Bahía.

En ese sentido, en el presente trabajo, nos proponemos realizar un estudio sobre los discursos religiosos acerca del matrimonio de la población esclavizada, los espacios físicos donde operaban dichos discursos religiosos y como impactaban en los amos y esclavizados tanto en el Perú y Brasil durante el periodo colonial. Para este hecho hemos recogido la idea propuesta por Stuart Schwartz, quien afirma que el matrimonio de esclavizados engloba cuatro elementos interconectados, 1) las normas legales y canónicas del matrimonio, 2) La realidad de la sociedad, 3) Las actitudes y acciones de los señores, y 4) Las percepciones y actuación de los cautivos ${ }^{1}$. Una base legal que actúa en un espacio donde la presencia de la Iglesia era central, consigue sin duda el conocimiento y la expansión de sus preceptos entre los grupos de amos y esclavizados, siendo este último proceso de conocimiento y expansión del catecismo religioso por parte de los esclavizados que nos interesa investigar entre dos áreas específicas como son el Perú y Brasil colonial.

Desde esta perspectiva, nuestro interés de estudiar Lima se basa en dos elementos importantes, el primero era uno de los espacios coloniales donde la presencia de la Iglesia fue gravitante. Solo en el siglo XVI existieron cuatro concilios provinciales en la ciudad de Lima, en ellos se tienen disposiciones favorables a la vida espiritual de los esclavos. Además, de ser el centro político y económico del virreinato del Perú. El segundo elemento, consiste en la presencia de la población esclavizada, Lima era el principal espacio donde habitaban los

\footnotetext{
${ }^{1}$ Schwartz, Stuart. Segredos internos: engenhos e escravos na sociedade colonial, 1550-1835. São Paulo: Companhia das Letras/CNP. 1988, p. 314.
} 
esclavizados, desde fines del siglo XVI la ciudad de Lima se convirtió en una ciudad negra, siendo los esclavos, libertos y demás castas los grupos predominantes en la ciudad capital.

En esa dirección, hemos ubicado documentación que nos permite conocer la interacción de la población esclavizada con la legislación eclesiástica y entender que no era solo un discurso escrito sobre el papel, sino fue usado recurrentemente por los diversos grupos sociales. Hemos ubicado en el Archivo Arzobispal de Lima, la sección de causa de negros que contiene una riqueza documental, lo cual nos ha permitido extraer para el siglo XVII, aproximadamente 300 demandas de esclavos contra sus amos, siendo la causal principal, la defensa del matrimonio.

En ese sentido, nos hemos propuesto realizar un trabajo comparativo con otra monarquía católica en América, como el Brasil, donde también, existió una legislación eclesiástica similar en su idea de formar una monarquía esclavista y cristiana al mismo tiempo. Por lo tanto, otorgó la libertad del contrayente y la posibilidad de la protección eclesiástica si los amos no respetaban la vida de casados de los esclavizados. Esta legislación que incluye al matrimonio de esclavos como asunto exclusivo de la Iglesia, fue la herramienta que permitió el reconocimiento de un derecho inherente a la condición humana del esclavizado. El tema por dilucidar en nuestra investigación es conocer, si la Iglesia en el espacio urbano del Brasil colonial, tuvo el mismo éxito para frenar el abuso de los amos contra el sacramento matrimonial de los esclavizados.

Existe un elemento importante que separa a las monarquías católicas de la América española y la América portuguesa, y era la existencia de la excomunión como una pena social, una herramienta que ejercía presión sobre los amos, la cual quedo impresa en los documentos conciliares del Perú (1582) y Nueva España (1585). ¿Por qué existió está marcada diferencia en los castigos a los amos infractores en estos dos espacios coloniales? La repuesta la debemos buscar analizando la especificidad de cada espacio, conociendo los intereses que estaban en juego, así como la importancia de la mano de obra esclava en Lima y Rio de Janeiro colonial. El impacto de la esclavitud no fue el mismo, en el siglo XVII, ocurrió una transformación importante, donde las economías de plantación tomaron el control de varias sociedades coloniales.

\section{1) DERECHO, ESCLAVITUD Y FAMILIA}


Las investigaciones sobre el derecho y su relación con la esclavitud han sido revitalizadas en los últimos años, la idea que el derecho era el brazo extendido del poder dominante o que simplemente reflejaba la estructura socioeconómica de la clase dominante ha sido desvirtuada. Ahora se puede apreciar que lejos de ser un campo estático, es un espacio institucional donde se observa los conflictos sociales, políticos y económicos. Por ejemplo, Keila Grinberg, afirma que: "nos últimos anos, estudaram as formas pelas quais o direito simultaneamente contribuiu para perpetuar o poder de proprietários sobre seus escravos e serviu como base a partir da qual escravos e libertos conseguiram desafiar este poder de seus senhores" (Grinberg 2004:218).

Es en esta línea que nuestro trabajo intenta presentar como el derecho al ser llevado a la práctica se transformaba en un espacio donde el poder es cuestionado a través de guerras microscópicas y cómo se estableció una lucha entre los amos y los esclavos por la hegemonía discursiva. Este dinamismo en la práctica jurídica tiene como actores principales a sectores sociales que supuestamente estaban excluidos del campo legal, ellos forman del parte del proceso que se denomina la construcción social del derecho. Una construcción marcada por el conflicto, la disputa y el consenso entre los diversos grupos sociales que participan en la arena jurídica.

Desde esta perspectiva, nuestro análisis sobre el derecho esclavista nos permite afirmar que a pesar que el derecho despersonalizaba al africano convirtiéndolo en objetomercadería, en un sujeto esclavizado, carente de personalidad jurídica, sin ningún tipo de voluntad ni decisión sobre su propia vida, es el mismo derecho que resuelve los márgenes de explotación del ser esclavizado, devolviéndole parte de su humanidad, reconociendo que puede bautizarse, casarse, denunciar los abusos de sus amos e incluso tener propiedades. Fernando Ortiz al comentar la importancia de Las Siete Partidas de Alfonso. El Sabio, señala que estas:

Leyes, en efecto, no autorizaban a confundir al esclavo con las cosas, antes, al contrario, lo consideraban, ya se verá como un sujeto activo de derechos, derechos hasta limitados si se quiere, pero derechos subjetivos al fin de los cuales no podía ser titular sino la persona humana, como tal calificada, mantenida jurídicamente (Ortiz 1988:309).

En ese sentido, reiteramos la idea que los esclavos lejos de colocarse de forma pasiva delante del derecho lo convirtieron en un espacio de reivindicación, así lo dejan entrever sus demandas, las cuales revelan un hábil manejo de la ley y de su contradicción, si bien era 
propiedad de su amo, su vida espiritual no era propiedad del amo. Por lo tanto, era compatible estar con el amo y con su esposa, más el primero tenía que respetar su espacio matrimonial.

Esta utilización del derecho eclesiástico-como medio de defensa de la familia esclavatuvo un enfrentamiento directo con el derecho de propiedad. ¿Cómo podrían los amos disponer libremente de su propiedad, si la Iglesia impedía la libre disposición o traslado de esclavizados en matrimonio? Desafortunadamente para los amos, el argumento del quebranto del matrimonio de los esclavizados colocaba a la Iglesia como la primera defensora. Si bien la propiedad era amparada por el derecho civil, la Iglesia influenció de manera gravitante para defender los derechos espirituales de los esclavos, hecho que fue socavando la autoridad de los amos. Este hecho fortaleció la idea entre la comunidad esclavizada que la conformación de lazos de parentesco a través del matrimonio representaba un espacio de muy difícil acceso para los amos.

Por otro lado, queremos destacar, que una cosa es hablar del derecho y otra de la práctica jurídica, es decir, en nuestro trabajo establecemos dos líneas muy claras, una es la Historia del derecho Eclesiástico en los espacios de la América colonial y otra es la Historia de la Justicia. En las próximas líneas nos detendremos a explicar cuáles fueron las normativas eclesiásticas que nacieron en la América colonial para los esclavizados, sea para la América española o portuguesa. Además, ya ingresando al campo de la aplicación de esta normativa, en lo que definimos como el campo de la justicia, nos interesa saber cómo, desde los Tribunales Eclesiásticos se administró la justicia para los hombres esclavizados. Debemos pensar en que el texto legal no es un elemento aislado, existe desde nuestro punto de vista, una vinculación dinámica entre el texto legal y el espacio de aplicación de la ley.

\section{2) LOS CONCILIOS CATÓLICOS EN LAS AMÉRICAS}

Los trabajos comparativos sobre diversos espacios de la América colonial española han ocupado parte de la historiografía Latinoamericana, no tanto así, los estudios comparativos entre la América española y la portuguesa, un hecho inexplicable porque tenemos experiencias coloniales similares, cada espacio con matices, pero con un marco general de dominación. Una de estas semejanzas es el hecho de pertenecer a monarquías católicas, un concepto que ha debido desarrollarse en la investigación comparativa de estos dos espacios coloniales. ¿Qué significaba para estos dos espacios pertenecer a monarquías católicas? ¿Fue gravitante en estas sociedades coloniales la presencia de la Iglesia católica? 
De estas interrogantes se desprenden del uso del concepto de monarquías católicas. Siendo nuestra principal inquietud saber ¿Cuáles son las semejanzas y diferencias en el discurso religioso sobre el matrimonio de esclavos en la América española y la América portuguesa?

Para ese fin, nuestro trabajo consiste en analizar fuentes del derecho eclesiástico respecto al matrimonio de esclavizados tanto en el Perú colonial como en Brasil, estas fuentes tienen un marco histórico distinto en su nacimiento, pero recogen el ideario establecido en el Concilio de Trento, realizado en el siglo XVI, el cual estableció:

\begin{abstract}
Un modelo matrimonial que impuso a la sociedad en las regiones católicas. Si el matrimonio era un sacramento, la autoridad de la Iglesia y su competencia sobre el vínculo eran incuestionables. Así, la Iglesia logró mantener su hegemonía jurisdiccional sobre el matrimonio. La mayoría de los cánones tridentinos insistían en su competencia para dirimir todas las cuestiones; el último canon resume a la perfección el estado de cosas al que se había llegado: "si alguno dijere, que las causas matrimoniales no pertenecen a los jueces eclesiásticos sea excomulgado" (Ghirardi, Mónica e Irigoyen, Antonio. 2009:245).
\end{abstract}

Este ideario debió ser puesto en práctica en los espacios de control de la Iglesia Católica, para el Perú colonial como lo hemos expresado, es el Tercer Concilio Límense que promueve la indisolubilidad del matrimonio y la libre elección de los cónyuges, no siendo impedimento su condición jurídica, esto llevo a que la prédica en la ciudad de Lima alcance a la población esclavizada que encontró en el sacramento matrimonial, un espacio de autonomía y de fortalecimiento de las redes de parentesco.

Esta puesta en práctica de los discursos religiosos a favor de los esclavizados en el Perú colonial sucedió a finales del siglo XVI, es decir, se estableció un ordenamiento jurídico que otorgaba derechos a los africanos y sus descendientes, en las primeras décadas de colonización y esta prédica fue difundida a través de la catequización. Esto nos lleva a pensar, en la existencia de una preocupación de las autoridades coloniales para establecer una sociedad católica jerarquizada donde sus integrantes así fuesen esclavizados obtuvieran derechos inherentes a su condición humana. Por ese motivo, estableció penas severas a los amos infractores, como la excomunión, que era la muerte social para cualquier persona que la recibía.

En los documentos revisados en el Archivo Arzobispal de Lima, era muy común encontrar la amenaza de excomunión a los amos que no respetasen la vida de casados de los hombres esclavizados. En varios casos, también se puso en ejecución este hecho, como lo grafican los siguientes ejemplos: En el año de 1652, Benito García, amo de Lucía Angola, 
solicita permiso al Tribunal Eclesiástico para trasladarla hacía la ciudad de Arica, argumentando que:

\begin{abstract}
Ha venido a mi noticia se a notificado auto a la panaderia por mandado de vuestra merced que no se me de a la dicha negra a pedimento del dicho su marido en lo qual e sido agraviado pues caso negado que no hubiese de volver estoy presto a dexar la dicha negra con su amo, y me de otra que me sirva en precio y trueque della pues no tengo quien me sirva ni sirva a mis hijos y el casamiento hubo sin licencia ni permiso mio, y no debe perjudicarme mayormente yéndome con toda mi casa ${ }^{2}$.
\end{abstract}

El Tribunal Eclesiástico accede a la solicitud del amo, desafortunadamente el amo no cumplirá con el acuerdo, siendo demandado por Matheo Anchico, esposo de Lucía, quien señala que "a tiempo de año y medio que llevo a la dicha mi mujer y no trata de devolverla en grave perjuicio del santo sacramento del matrimonio $3 "$. A pesar del pedido el amo hace caso omiso a la demanda de Matheo, pasando 3 años, sin que Lucía consiga hacer vida conyugal. En uno de los viajes a Lima de Benito García, Matheo Anchico solicita al Tribunal Eclesiástico, que no deje salir de la ciudad al amo de su esposa hasta que la regresa a la ciudad, solicitando sea excomulgado por atentar contra el matrimonio. De esta forma, el juez provisor demanda a Benito García ordenando que:

\title{
mandava y mando se notifique al dicho Benito Garcia no salga desta ciudad en manera alguna hasta tanto que haya traído a ella a la dicha Lucia Angola para que haga vida maridable con el dicho Mateo Anchico su marido y que lo cumpla en virtud de santa obediencia y so pena de excomunión mayor la sentencia canonica. Premisa en ipso facto y con citación para la tablilla y así lo proveyó y firmo ${ }^{4}$.
}

El incumplimiento de la palabra otorgada era mal vista por las autoridades eclesiásticas, que no tuvieron mayor opción de negarle la salida de la ciudad a Benito García hasta que trajera de vuelta a Lucía, teniendo como amenaza la posibilidad de una excomunión por impedir la libre cohabitación matrimonial. En 1676 Joan de Omonte demandó a José Carrillo, amo de su esposa Dominga de la Cruz, porque la han "llevado a embarcar para el puerto de Arica a la dicha mi muger y está en el puerto del callao, a donde la han enviado y esta para salir el navío para dicho puerto" ${ }^{5}$ El Tribunal Eclesiástico ordenó al amo José Carrillo y al capitán del navío que no se lleven fuera de la ciudad a la esposa de Joan Omonte, bajo la amenaza de excomulgarlos. Sin embargo, estos personajes omiten la amenaza de la Iglesia, hecho que obtiene la respuesta del tribunal "por incursos en dicha censura y mando

\footnotetext{
${ }^{2}$ A. A. L. Sección. Causas de negros. Leg. XII. Exp. 3. Año. 1652.

${ }^{3}$ Ídem.

${ }^{4}$ Ídem.
}

${ }^{5}$ A. A. L. Causas de negros. Leg. XVIII. Exp.31. Año 1676. 
sean puestos en la tablilla por públicos excomulgados y se despachen declaratorias en forma y se les notificase el auto para que se abstengan de la comunicación con los fieles" ${ }^{\circ}$.

La excomunión era sin duda un elemento muy eficaz contra el abuso de los amos y varios de ellos fueron castigados de esta forma. Para el caso de Nueva España, el Tercer Concilio Provincial, también dispone que "ningún español obligue a indio o esclavo alguno a contraer matrimonio; ni por fuerza les impida el casarse libremente a su gusto con quien quiera, bajo pena de excomunión” (Martínez 2004:224). María Elena Cortes (2001), ha demostrado que esta prédica no fue solo tinta en papel, sino que se hizo efectiva por los propios esclavizados en el virreinato de Nueva España.

Por otro lado, en el Brasil colonial, la historiografía sobre la familia esclava ha sido desarrollada de forma importante, siendo el trabajo de Manolo Florentino y José Roberto Góes, uno que reafirma la idea de la existencia de la familia esclava, en condiciones de cautiverio al afirmar que:

\begin{abstract}
A família escrava não era de modo algum mero epifenômeno, nem estava diluída no escopo patriarcal dos proprietários. Tampouco sucumbia a violência nem era, primariamente, um veículo de controle senhorial. Pelo contrário, ao caracterizar-se enquanto meio de organização e pacificação dos cativos, ela lhes fornecia sólidos pilares para a construção e reconstrução de padrões mentais e de comportamento próprios de uma cultura afro-brasilera (Florentino y Goes 1997:44-45).
\end{abstract}

Los amos buscaban apaciguar cualquier intento de rebelión esclava en sus haciendas concediendo espacios para la constitución de la familia esclava que se transformó en un instrumento de paz social dentro de sus propiedades. Sin embargo, estas negociaciones políticas no son las únicas herramientas que permiten la constitución de familias al interior de la comunidad esclava, existe una legislación canónica que se debe tener en cuenta a la hora de pensar en los matrimonios de esclavos. Aunque tardía en comparación con otros espacios coloniales de la América colonial, esta legislación recogió en parte el ideario del Concilio Tridentino, respecto a temas como la indisolubilidad del matrimonio y la libre elección del cónyuge y estos derechos según la historiografía brasilera no fueron reconocidos por los amos porque lo consideraban subversiva y atentaba contra su soberanía doméstica (Castelnau 2011:394).

Según Carlos Engemann, existían dos espacios donde la familia esclava se desarrollaba, primero en las haciendas, donde existía una cantidad importante de esclavos,

${ }^{6}$ Ídem. 
siendo permitido por los amos la conformación de la familia esclava, esto, se origina porque el volumen poblacional de esclavos permitió tener un poder de negociación con los amos, obteniendo la concesión de pequeños lotes de tierra. Esto no era un acto de benevolencia, por el contrario, esta negociación obedece a la existencia de un temor al conflicto (Engemann 2005:1993). Además, la existencia de matrimonios dentro de la comunidad permitía asegurar la reproducción de la mano de obra y que ella permaneciera dentro de la propiedad. El segundo espacio, es la ciudad y los pequeños propietarios de esclavos, aquí los problemas que producían la libre elección o la indisolubilidad del matrimonio eran evidentes, porque generaba una autonomía en los esclavos que era rechazada por los amos. Siendo el principal conflicto el que se generó a partir de la puesta en práctica de Las Constituciones del Arzobispado de Bahía, las cuales no fueron recusada por los amos, porque afectaban sus intereses patrimoniales. Este rechazo tuvo se fortaleció porque en gran parte porque no existía una condena a los amos que desafiaban la autoridad de la Iglesia.

Aquí encontramos un hecho que es relevante en los dos procesos de colonización en las Américas, después de producido el Concilio de Trento, este alcanzó al poco tiempo un fuerte impacto en las colonias de España en América, produciéndose los concilios católicos, tanto en Nueva España y Lima, destacando principalmente los realizados en la década de 1580, que plasmaron en sus conclusiones el ideario de Trento respecto al matrimonio, considerando que era indisoluble y que debía existir libertad de elección de los cónyuges. Además de ello, en el caso que alguien impidiese la libre cohabitación matrimonial o no permitiese el matrimonio, era excomulgado inmediatamente. Las colonias americanas al adecuar estos preceptos lo hicieron de acuerdo con sus realidades, en las colonias españoles, la adecuación tuvo que tener en cuenta a la gran población indígena y a la presencia afrodescendiente, para el caso del Brasil, la presencia africana y sus descendientes eran mayoritaria, de esta forma la adecuación tuvo que tomar en cuenta estos hechos.

Para los dueños de esclavizados de la América portuguesa, la idea de reconocer el derecho a la libre elección era contraproducente a sus intereses. Distinta figura en la América española, donde la excomunión hizo que hasta los amos más reacios acataran las normativas de los concilios católicos, hemos encontrado varios casos donde se hizo efectiva esta sanción. Pero ¿qué significaba la excomunión? En una sociedad marcada por la presencia de la Iglesia, el no permitir asistir a misa, comulgar y que su nombre estuviera en la puerta principal de la Iglesia, era simplemente la muerte social. De esta forma, la excomunión representaba una 
pena canónica por una falta consideraba grave. Por ese motivo, los amos tuvieron que obedecer las disposiciones de la Iglesia a favor de los esclavos, incluso si impedían la asistencia a misa también eran castigados con la excomunión.

El estructurar una legislación que otorgaba derechos a los esclavizados, nos muestra el interés de parte de las autoridades de establecer una sociedad esclavista y católica a la vez, desde las primeras décadas de dominación colonial. Una legislación donde se reconoce la humanidad del hombre que había sido despojado de su libertad, reconociéndole derechos mínimos y defendiéndolo de los abusos de los amos. Este hecho marcó una diferencia importante con la América portuguesa, donde si bien la presencia esclavista había sido más importante en términos cuantitativos, la legislación canónica fue tardía.

\subsection{LOS CONCILIOS LIMENSES:}

En la ciudad de Lima durante el siglo XVI se organizaron 4 concilios católicos 1551 , 1567, 1583 y 1591, en estas reuniones la Iglesia católica dictaba las normas para fortalecer el ideal de sociedad cristiana que deseaba establecer en el Perú colonial. El fin central de estas congregaciones del clero, era ponerle control a la vida libre de los habitantes de esta parte del Nuevo Mundo, ningún estamento de la sociedad podía quedar fuera de su control, su lógica de establecer una sociedad católica donde todos los seres humanos fueran incluidos, no se contradecía con el orden social jerárquico de la fundada sociedad colonial. Por el contrario, se fortalecían las diferencias entre los individuos, si bien podría tener acceso a los sacramentos, como el bautizo, matrimonio, asistir a misa, entre otros. Esto solo era un reconocimiento a su condición humana mas no existía la idea de una sociedad igualitaria, tanto indígenas como negros libres o esclavizados quedaban fuera de la función sacerdotal. Aun así y sin pretenderlo, la legislación canónica emanada de los Concilios Católicos sirvió como base legal para cuestionar el poder mal ejercido de los amos en Lima colonial.

De esta forma, podemos afirmar que los Concilios Limenses' regularon la vida espiritual de los esclavizados en el mundo colonial de la ciudad de Lima, significando este hecho, su reconocimiento como seres humanos al validarles sus derechos naturales, siendo el bautismo el primer contacto con la fe cristiana, la cual se fortalecía en la catequesis diaria que recibían los diversos grupos de la sociedad colonial.

Por eso creemos, que el éxito de la legislación canónica que favorecía a los esclavizados tiene su punto fuerte en la catequesis, por ejemplo, desde el Primer Concilio, 
realizado el año de 1551, se demandaba a los amos enviar a sus negros esclavizados a recibir doctrina en la iglesia los domingos, los días de fiesta y en las tardes después del horario de almuerzo:

\begin{abstract}
Estatuimos y mandamos que todos los domingos en nuestra iglesia catedral y en todas las demás catedrales y parroquiales de todo nuestro Arzobispado e Provincia los curas requieran y amonesten a sus parroquianos que envíen sus hijos, indios e indias y negros de servicio a la iglesia ser informados en las cosas de nuestra santa fe, y para que mejor se junten en todos los dichos días de fiesta y en la cuaresma dos días en cada semana a la una después de comer se taña la campana por espacio competente para que todos tengan lugar para poderse juntar (Vargas Ugarte 1951:44).
\end{abstract}

Por este hecho discrepamos que con la idea (Trazegnies 1989, Cosamalon y Arrelucea 2015, Grinberg 2018) que fueron Las Siete Partidas de Alfonso X la base legal que reguló la esclavitud en los reinos de ultramar. Si bien Las Partidas no pueden ser excluidas del ordenamiento jurídico colonial, fue la legislación canónica la que estuvo más vinculada a la sociedad colonial. Primero porque fueron emanadas desde los centros coloniales, sea Nueva España o Lima, y segundo, porque fueron permanentemente expuestas por los sacerdotes en la catequesis diaria. Es decir, Las Partidas fueron un discurso jurídico muy alejado de la sociedad no letrada, en tanto, los documentos conciliares fueron divulgados cotidianamente a indígenas, negros libres o esclavizados. Además, que fueron adaptados a la realidad local como lo expresa Rubén Vargas Ugarte al señalar que el Primer Concilio de Lima encierra algo peculiar y con eso salía al paso a las dificultades que ofrecía la evangelización en América (Vargas Ugarte 1951:12).

Nuestra idea es presentar a los documentos conciliares como parte de un proceso de normativa cristiana que buscaba moldear a las sociedades coloniales bajo preceptos católicos y que se adecuaban a la realidad del espacio donde se originaban. Por ejemplo, en la América española, sean en Nueva España o el Perú, la legislación canónica estuvo en gran medida orientada a la evangelización de los indígenas, en la América portuguesa, este hecho varió significativamente.

\title{
2.2.) LOS MATRIMONIOS DE ESCLAVOS EN LAS CONSTITUCIONES DEL ARZOBISPADO DE BAHÍA
}


En la América portuguesa también se protegió a través de documentos eclesiásticos los matrimonios de esclavos, aunque era algo tardío en comparación con los dominios españoles ${ }^{7}$, dichos documentos contienen el mismo espíritu de defensa de la vida espiritual de los esclavizados y hombres libres de color, resaltando la gran influencia del Concilio de Trento. Las Constituiçoes Primeiras do Arcebispado da Bahía puestas en vigor a partir de 1707, es el primer documento redactado en la América portuguesa donde se reglamentaban los matrimonios de esclavos y quienes se podían casar con personas esclavas o libres. Rescatando todo el espíritu del Concilio de Trento respecto al matrimonio.

Esta defensa del matrimonio obedecería no sólo al interés de proteger el sacramento sino también a impedir el amancebamiento o relaciones indebidas que generaban caos y desorden en la sociedad colonial. Sin duda se buscaba que la sexualidad se ejerciera dentro de los linderos del matrimonio y este destinada solo a la procreación. Así lo confirma, esta cita "O concubinato ou amancebamento consiste em uma ilícita conversação por tempo considerável”. (CAB. 979) De esta forma, se promovía la unión matrimonial, otorgándole al esclavizado u hombre libre de color la libertad de decisión sobre la elección de su cónyuge dentro de su grupo étnico. Para Fernando Torres Londoño, en el siglo XVIII la Iglesia refuerza el carácter sacramental al ejercer un mayor control sobre la administración de los sacramentos. (Torres Londoño 115).

En el caso de los matrimonios mixtos podemos encontrar algunos elementos que favorecerían más a los amos, por ejemplo, Charlotte de Castelnau, afirma que el caso de los matrimonios mixtos, la solución propuesta por el Tribunal Eclesiástico para permitir que los esclavos se casaran libremente, era no ir en contra de los intereses de los amos, por lo tanto, se debía firmar un compromiso por parte del cónyuge libre que se comprometía a seguir a su esposo esclavo a todos los lugares donde su señor vaya o lo venda (Castelnau 2016:7-8). Este hecho era beneficioso para los amos, que ahora tenían una mano de obra adicional a la de su esclavo, incluso podría presionar al propio esclavo con negarle la cohabitación con su esposa si no tenía un buen desempeño en el trabajo. Por eso, no cabe duda, que estos matrimonios

${ }^{7}$ Charlotte de Castelnau señala que si bien las constituciones del arzobispado de Bahía son tardías (1707) el matrimonio de esclavos en la América portuguesa se regía por las constituciones del arzobispado de Lisboa de 1646, aunque desde el siglo XVI se tienen referencias a documentos emitidos en Lisboa en 1568 y por el papa Gregorio XIII en 1585, en los cuales se habla sobre la importancia de respetar el matrimonio de los esclavos. Castelnau Charlotte de. O ideal de uma sociedade escravista: Direito canônico e matrimonio dos escravos no Brasil colonial. Em A igreja no Brasil. Normas e prática durante a vigência das constituições primeiras do Arcebispado do Bahia. Feitler, Bruno y Sales Souza, Evergton. Editora Unifesp. São Paulo. 2011. Brasil. Pág. 358. 
podrían haber sido alentados por los amos e incluso ser ellos quienes paguen los gastos del proceso matrimonial, pensando en los réditos que producirían una mano de obra adicional. Este hecho para Charlotte de Castelnau, era regido por el derecho consuetudinario, porque:

\footnotetext{
Garantia que casamentos mistos não interferissem na soberania doméstica dos senhores de escravos. A liberdade do senhor para enviar a lugares distantes ou vender seu escravo não poderia ser obstruída pelo fato de ele casado, então a Igreja obrigava o cônjuge livre a seguir o cônjuge escravo (Castelnau 2016:23).
}

Aun así, creemos que en el caso de los matrimonios de esclavos estas disposiciones consolidaban a la familia como elemento indisoluble dentro de la sociedad esclavista, creando un espacio propio donde la influencia de los amos era escasa, creándose vínculos consanguíneos, amicales y una identidad en común entre los esclavos, alimentada por sus experiencias comunes, valores y memoria compartida que fortalecían a la comunidad esclava (Slenes 1999:49). En resumen, estas disposiciones nos muestran claramente que los esclavizados también eran sujetos de derecho en la América portuguesa, así lo destacan Joao Fragoso y María Fátima Gouvea:

\begin{abstract}
Uma vez incorporados ao espaço da mesma monarquia católica, adquiriam a condição de servo civil, o que implicava no reconhecimento de ter alma, ser cristianizado pelo batismo e por ele ingressarem no mundo das relações pessoais, leia-se, compadrio, sendo isto reconhecido pela Igreja e pelo rei. Em outras palavras, se cativos na condição de pessoas já eram agentes, no espaço da monarquia lusa elas transformam-se em escravos cristãos com seus devidos direitos (Fragoso y Gouvêa 2014:12).
\end{abstract}

Aunque en la práctica estas disposiciones legales fueron algo tardías en su aplicación, al parecer recién el siglo XIX, tenemos un acercamiento más notorio de los esclavizados a la vía legal. Esto refuerza la importancia de los estudios comparados, porque nos permiten observar, cómo siendo monarquías hispanas la española y la portuguesa y regidas por la misma confesión religiosa, la importancia de la Iglesia en el otorgamiento de derechos a los esclavos no tuvo la misma rapidez en la monarquía lusitana.

Como lo hemos mencionado, en los estudios sobre la esclavitud en la América portuguesa, se tiene la idea extendida que estos derechos no eran reconocidos por los amos y son ellos los que permitían a sus esclavizados casarse o iniciar alguna acción legal bajo su consentimiento, no existiendo derechos sino concesiones señoriales. La legislación canónica era muy precisa en otorgarle la libertad de elección a los cónyuges: 
Conforme o direito Divino e humano, os escravos e escravas podem casar com outras pessoas captivas, ou livres, e seus senhores lhes não podem impedir o Matrimonio, nem uso dele em tempo, e lugar conveniente, nem por esse respeito os podem tratar pior, nem vender para outros lugares remotos, para onde o outro, por ser cativo, ou por ter outro justo impedimento, o não possa seguir" (CAB 2011:125).

Para las Constituições Primeiras do Arcebispado da Bahia, también era importante impedir los amancebamientos señalando que era muy usual que los esclavizados vivan amancebados y que esta responsabilidade era de los amos. Por lo tanto, no se debía amonestar a los amancebados sino a los amos, porem judicialmente se fará a saber a seus senhores do mao estado, en que andao; advertindo-os, que se não puzerem cobro nos ditos seus escravos, fazendo-os apartar do ilícito trato, e ruim estado, ou por meio de casamento, que o mais conforme a Lei de Deus (CAB 2011:340-341). Este articulo era la insistencia a un problema que se había vuelto cotidiano en el Brasil colonial, por eso se incidía que los amos no debían permitir el estado de condenación de sus esclavizados:

\begin{abstract}
Os senhores tomam suas consciências as culpas de seus escravos que por meio do temor se deixam muitas vezes estarem, e permanecem em estado de condenação. Pelo que lhe mandamos, e encarregamos muito, para que não lhes ponham impedimentos aos seus escravos para que se casarem, nem com ameaças, e mão tratamentos lhes encontrem os uso do matrimonio em tempo, e lugar conveniente, nem depois de casados lhes vendam para partes remotas de fora para onde suas mulheres por serem escravas ou terem outro impedimentos legitimo não possam seguir (CAB 2011.125).
\end{abstract}

Según el documento conciliar, para los amos quedaba reducida la libre disposición de su propiedad, la iglesia impedía por cualquier motivo que los esclavos casados se encuentren alejados del hogar conyugal sea por venta o un simple traslado a otra ciudad. Estas disposiciones del arzobispado de Bahía solo reproducen la doctrina católica en torno al matrimonio, el respeto al derecho canónico y a la doctrina de la iglesia en defensa de los esclavizados y sus derechos elementales. Asimismo, quedaba a cargo de los curas, vicarios y capellanes, saber si los esclavizados conocían de la doctrina católica antes de casarlos. (CAB 2011:125). Una vez superado este punto los esclavizados quedaban aptos para el matrimonio. Porque era un derecho humano casarse y los amos estaban en la obligación de cumplir con esa disposición sin perjuicio de su propiedad, dado que el principal argumento de los amos para negarse al matrimonio de sus esclavizados era la idea asumida que el casamiento significaba la abolición de la condición servil del esclavizado. La persistente negativa de los amos según 
las Constituciones los colocaba en pecado mortal, no se estimaba la excomunión como castigo como se practicaba en la América española.

Por otro lado, el evitar la venta o traslado de uno de los cónyuges era vital para el mantenimiento de la familia esclavizada, la Iglesia señalaba los castigos si incumplían sus órdenes, siendo la excomunión el castigo más severo. El tema de esta investigación es conocer si esta legislación fue utilizada en la práctica en la América portuguesa, es un camino que hemos habilitado para un trabajo comparativo ya no sólo a nivel de legislación canónica sino de práctica judicial, teniendo como causal, la defensa de la institución matrimonial. Aunque debemos tener en cuenta, la especificidad de los espacios, Russell-Wood (2005) señala que existían diferencias en la conformación de la familia esclava, entre áreas de plantación, minería y espacios urbanos.

En el primer caso, los amos alentaban los matrimonios de esclavos porque de esta forma su propiedad se acrecentaba y, por lo tanto, tendría mano de obra para emplearlo en sus haciendas. En el caso de las áreas de minería afirma que: e muito evidente a baixa incidência de casamentos entre escravos, ou aliás na população total (Russel-Wood 2005:172). El autor señala que las pocas mujeres negras que existían preferían el concubinato con los blancos, porque daba mayor seguridad que el matrimonio con un esclavo. Asimismo, las posibilidades de conseguir su libertad aumentaban considerablemente. Otro elemento que impedía un mayor número de matrimonios era la alta tasa que se pagaba por los tramites a la Iglesia ${ }^{8}$ prefiriendo los esclavos pagar un funeral católico que un matrimonio (Rusell-Wood 2005:173).

Stuart Schwartz, al comentar el impacto de las Constituciones en la vida de los esclavos señalaba que no representaron ningún cambio de importancia, si bien otorgaba límites al poder de los amos, al final terminaba consolidando el régimen esclavista. Por lo tanto, era apenas era una declaración piadosa sin efectos prácticos. Sin embargo, Charlotte de Castelnau discrepa de esta idea, porque es concebir al arzobispado de Bahía como una fuerza antiesclavista, y su función no fue tal sino la de adecuar una normativa vigente de la Iglesia a la realidad del Brasil colonial (Castelnau 2011:358).

\footnotetext{
${ }^{8}$ Este hecho, difiere al caso del Perú colonial, donde no se ha visto este tipo de tasas para la realización de matrimonios de esclavos, por el contrario, tenían derecho a un defensor de oficio, como el procurador de menores, que desafortunadamente no se ha encontrado una mayor presencia en los documentos.
} 
También afirma que las Constituciones deben ser leídas como un texto normativo y no descriptivo que buscaba crear el perfil de una sociedad esclavista y cristiana al mismo tiempo dicho interés no solo partía de la Iglesia sino de las propias monarquías católicas. En esa misma línea Carlos Alberto Zeron señala que "tambén seria pertinente interpretar a posição da Igreja, nas Constituições Primeiras, como a de uma instituição reduzida a um papel meramente moralizador, constrangida a agir apenas por meio do sermão e da confissão" (Zeron: 2011:352). Al parecer, el hecho que la violación de los derechos sacramentales como la libre elección conyugal, terminaban caricaturizando el poder de la Iglesia sobre los amos. La condena moral era insuficiente para proteger a los esclavizados de los abusos de poder de sus señores, entonces, el poder señorial se fortaleció tanto así, que termino transformando derechos en concesiones señoriales.

Por outro lado, Adriana Campos y Patrícia Merlo, concluyen que "Ao contrário historiografia que negava a constituição da família escrava no Brasil, a leitura dessa legislação canônica permite-nos duvidar que as altas hierarquias não reconhecessem a legitimidade do matrimonio entre escravos" (Campos y Merlo 2005 345). El matrimonio no fue una institución negada a los esclavizados, por el contrario, estaba dentro de su obligación del buen cristiano, el problema radicaba en la negativa de los amos a aceptar dichos matrimonios. Por su parte, Luiz Fernando Veloso destaca que, a pesar de la resistencia de los amos, la Iglesia se inmiscuyó en asuntos que en esa época eran considerados privados, instando a los amos a respetar la indisolubilidad del matrimonio. (Velosso 2014:307). Sin embargo, este mismo autor señala que el matrimonio de esclavos era minoritario, pero no insignificante, esté bajo índice responde a la negativa de los amos de permitir la libre elección conyugal.

En ese sentido, nuestro interés radica en conocer si esta legislación tuvo un impacto real en la sociedad esclavista brasilera, conocemos que existían segmentos de la sociedad que estaban preocupados por adecuar las prácticas cotidianas del esclavismo al régimen matrimonial establecido por el Concilio de Trento. Aun así, el establecimiento del derecho a la libre elección matrimonial de los esclavizados no ha tenido la atención necesaria en la historiografía y menos desde la perspectiva comparada. Teniendo en cuenta la importancia que la Iglesia otorgó al derecho de la libre elección conyugal y la indisolubilidad del matrimonio entre esclavos, siendo estos procesos, un importante instrumento de sociabilización dentro de las sociedades esclavistas. 


\section{CONCLUSIONES:}

Las monarquías católicas en la América colonial buscaron crear una sociedad católica y esclavista al mismo tiempo, aunque en tiempos distintos. Este hecho fue significativo porque en la América española desde el siglo XVI, se creó una legislación donde se reconocían derechos a los hombres esclavizados. Estos derechos eran parte del debate que se había generado en el Concilio de Trento y se replicó tanto en el Perú colonial a través del Tercer Concilio Límense, como en el virreinato de Nueva España. Considerándose que los hombres esclavizados tenían como derecho asistir a misa, casarse según su elección y a la indisolubilidad del matrimonio.

Estos derechos fueron defendidos por los esclavizados en los fueros eclesiásticos con éxito, generándose una resistencia a la autoridad mal ejercida de los amos. Pero el elemento más importante que permitió la consolidación de estos derechos fue la amenaza de excomunión contra los amos infractores, algo que no quedo en la práctica. La Iglesia excomulgó a varios amos que se negaron a respetar la vida espiritual de sus esclavizados.

Para la América portuguesa, la constitución de la sociedad esclavista y católica fue tardía, si bien existió una legislación emanada desde la metrópoli recién a inicios del siglo XVIII, se produce un concilio católico que recoge el ideario del Concilio de Trento, sancionando a los amos que impiden la consolidación de la vida matrimonial. Sin embargo, esta sanción se podría afirmar, era nominal, solo estaban en pecado mortal. La figura de la excomunión no fue incluida en Las Constituciones del Arzobispado de Bahía, esto motivó a los amos a desacatar e impedir la libre elección matrimonial de sus cautivos.

Creemos que la tardía elaboración del documento conciliar, permitió a los amos moldear a la sociedad católica a sus intereses. Si lo esclavizados se casaban con la persona elegida, si cohabitaban con sus esposas o tenían algún beneficio, era por la voluntad del amo, transformándose sus derechos en una concesión señorial. Este proceso sin duda difiere de lo ocurrido en la América española, donde la Iglesia controló la vida espiritual de los esclavos con relativo éxito. 


\section{BIBLIOGRAFÍA}

Arrelucea, Maribel. Lágrimas, Negociación y Resistencia Femenina: Esclavas litigantes en los tribunales de Lima 1760-1820. Revista Summa Historiae, N.2. Lima. 2007.

Campos, Adriana y Merlo, Patrícia. Sob as bênçãos da Igreja: o casamento de escravos na legislação brasileira. Topoi. Revista de História de pós-graduação em História Social da UFRJ. Vol.6, n.11, jul-dez. 2005. Rio de Janeiro.

Castelnau Charlotte. $O$ ideal de uma sociedade escravista: Direito canônico e matrimonio dos escravos no Brasil colonial. Em A igreja no Brasil. Normas e prática durante a vigência das constituições primeiras do Arcebispado do Bahia. Feitler, Bruno y Sales Souza, Evergton. Editora Unifesp. São Paulo. 2011.

Castelnau, Charlotte. Os filhos obedientes da Santíssima Igreja. Escravidão e estratégias de casamento no Rio de Janeiro do início do século XVIII. 2017.

De Egaña, Antonio. S.J. Historia de la Iglesia en la América española. Desde el descubrimiento hasta comienzos del siglo XIX. Biblioteca de Autores Cristianos. Madrid. 1966.

Engemann, Carlos. Da comunidade escrava e suas possibilidades, séculos XVII a XIX. In: Florentino, Manolo (org.). Tráfico, Cativeiro e Liberdade: Rio de Janeiro, séculos XVII-XIX. Rio de Janeiro: Civilização Brasileira. 2005.

Florentino, Manolo e Góes, José Roberto. A paz das senzalas. Famílias escravas e tráfico atlântico, Rio de Janeiro c. 1790- c.1850. Rio de Janeiro: Civilização Brasileira. 1997.

Fragoso, Joao y Florentino, Manolo. O Arcaísmo como projeto. Mercado Atlântico, Sociedade Agrária e Elite Mercantil no Rio de Janeiro, c. 1790-c.1840. Diadorim. Rio de Janeiro. 1993. 
Ghirardi, Mónica e Irigoyen, Antonio. El matrimonio, el Concilio de Trento e Hispanoamérica. Revista de Indias, 2009, vol. LXIX. Núm. 246. 2009.

Gonzales Jáuregui, Yobani. Los esclavos de Lima y su defensa del matrimonio en el siglo XVII. Revista Artifícios. N. 2. mayo 2015.

Grinberg, Keila. Escravidão, Direito e Justiça no Brasil Colonial. Resenhas em Tempo, n 17, pp.217-222. Rio de Janeiro. 2004.

Hünefeldt, Christine. Esclavitud y familia en el Perú en el siglo XIX. Revista del Archivo de la Nación. N. 7 Lima. 1984.

Hünefeldt, Christine. Jornales y esclavitud: Lima en la primera mitad del siglo XIX. En Economía. Revista del departamento de economía de la PUCP. Vol. X. N. 19. 1987.

Hünefeldt, Christine Mujeres: esclavitud, emociones y libertad. Lima 1800-1854. Documento de trabajo. N. 24. IEP. Lima. 1988.

Klein, Herbert. "Anglicanism, Catholicism and the negro slave". Comparative Studies in Society and History, 8, n3, 1966.

Machado, Cacilda. Casamentos de escravos e negros livres e a produção da hierarquia social em uma área distante do tráfico atlântico (São José dos Pinhais-PR, passagem do XVIII para o XIX). Nas Rotas do Império. Fragoso, João. Florentino, Manolo. Jucá, Antônio Carlos. Campos, Adriana. Organizadores. Edufes. Vitoria. 2006.

Mattos, Hebe Maria. A escravidão moderna nos quadros do Império português: O Antigo Regime em perspectiva atlântica. In Fragoso, Joao, Maria Fernanda Bicalho e Maria de Fátima Gouvêa (Orgs). O Antigo Regime nos trópicos: a dinâmica imperial portuguesa (séculos XVI-XVIII). Rio de Janeiro: Civilização Brasileira. 2001.

Merlo, Patrícia. A família escrava nas tramas do cotidiano. In Dimensões, vol.26. 2011. Ortiz, Fernando. Los negros esclavos. Editorial de Ciencias Sociales. La Habana. 1988. 
Russell-Wood, A. J. R. Escravos e Libertos no Brasil Colonial. Civilização Brasileira. Rio de Janeiro. 2005.

Slenes, Robert. Na Senzala, Uma Flor. Esperanças e recordações da família escrava Brasil Sudeste, século XIX. Editora Nova Fronteira. RJ. 1999.

Schwartz, Stuart B. Segredos internos: engenhos e escravos na sociedade colonial, 15501835. São Paulo: Companhia das Letras/CNP. 1988.

Tardieu, Jean-Pierre: Los Negros y la Iglesia en el Perú, siglos XVI - XVII. 2T. Ediciones. Afroamérica. Centro cultural afroecuatoriano. Ecuador. 1997.

Trazegnies, Fernando de. Ciriaco de Urtecho. Litigante por amor. PUCP. Lima. 1989. 